\title{
RISCO E CONTRATO NA PERSPECTIVA DA TEORIA DOS SISTEMAS DE NIKLAS LUHMANN
}

\section{RISK AND CONTRACT FROM THE PERSPECTIVE OF SYSTEMS THEORY BY NIKLAS LUHMANN}

\section{David Denner de Lima Braga ${ }^{1}$ Eduardo Henrique Lopes Figueiredo ${ }^{2}$}

Resumo: O presente trabalho procurou analisar o risco contratual a partir da teoria dos sistemas autopoiéticos de NiklasLuhmann. Para isso utiliza-se da observação de segunda ordem, cuja unidade analítica parte da lógica das formas de Spencer Brown, transitando por formas de diferenças. Enquanto a maior parte dos autores trabalha em um esquema risco/segurança, este estudo trabalha, com Luhmann, em um esquema risco/perigo. A pesquisa dirigiu sua atenção a dois momentos: o da modernidade e o da contemporaneidade e se desenvolveu atenta aos seus contrastes, tanto ao cuidar do risco quanto ao cuidar do contrato. Quanto ao risco, os modernos criaram o mito da calculabilidade,acreditavam que a probabilidade e o cálculo podiam contornálos.Quanto ao contrato, deram-lhe uma formulação sofisticada,sobre cujas bases se trabalha até hoje. A contemporaneidade desafiou essas noções. O risco é incontornável e o contrato, em sua formulação abstrata, vem sendo revisto, sob variados pontos de vista, para que seja instrumento de igualdade e liberdade, uma vocação que ele insiste em descumprir. O estudo do risco no contrato permite notar que malgrado seu papel relevante na vida das pessoas e das organizações, o contrato não é garantiados valores segurança e igualdade.

Palavras-Chave: Risco. Perigo. Incerteza. Contratualidade. Modernidade.

Abstract: The present work aimed to analyze the contractual risk from the point of view of Autopoietic Systems Theory. This study makes use of second order observation, which analytical unity follows Spencer Brown calculus of forms, moving through forms of difference. Whilstmost authors work under the scheme risk/security, this study works under the luhmannian scheme risk/danger. This research draw its attention to modernity and contemporaneity and had developed attentively to their contrasts, when it discusses risk, as well when it discussescontractuality. As to risk the modern had created the myth of calculability, they believed that probability and calculus were able to skirt risk.As to contract they gave it a sophisticated formulation in which grounds one works nowadays. Yet contemporaneity has defied this ideas. Risk is unavoidable and contract, as legal transaction, is being reviewed in many ways, to be able to be a mean to achieve equality and liberty, a vocation that it is far from fulfill. The study of contractual risk has a big role in the life of persons and organizations, but it can give no guarantee to achieve equality and security.

KEY-WORDS: Risk. Danger.Uncertainty.Contractuality. Modernity.

\footnotetext{
1 Graduado em Direito e Letras Português pela Universidade Estadual de Montes Claros. Mestre em Constitucionalismo e Democracia pela Faculdade de Direito do Sul de Minas.

${ }^{2}$ Graduado em Direito pela Universidade Estadual de Londrina (1994). Desenvolveu estudos de especialização em docência do Ensino Superior na Pontifícia Universidade Católica do Paraná PUC- PR (2004). É mestre em Direito das Relações Sociais pela Universidade Federal do Paraná (2000) e Doutor em Direito do Estado (2006), também pela Universidade Federal do Paraná. É pesquisador e professor do Programa de Pós Graduação da Faculdade de Direito do Sul de Minas (conceito 4 CAPES), o qual coordenou entre 2010 e 2013. É, também, professor adjunto nível AD-D do Departamento de Direito Público da Universidade Estadual de Londrina. Suas atividades como pesquisador envolvem História do Estado de Direito e do Direito Público, História do Constitucionalismo e Teoria Política. É pós doutorando em direito econômico e político pela Universidade Presbiteriana Mackenzie.
} 


\section{INTRODUÇÃO}

O presente estudo parte de uma proposta simples, pelo menos em princípio, o estudo dos contratos sob uma perspectiva do risco, mas que não permanece trivial por conta do referencialaltamente abstrato da teoria dos sistemasautopoiéticos, cuja base é uma teoria do conhecimento de índole construtivista.

O construtivismo ficou muito popular em razão das constantes mudanças por que a sociedade passou, tornando-se, em certo momento, muito difícil não ser um construtivista (ANDERSEN, 2003, p. IX). Isso leva à questão da metodologia que empregamos. Provavelmente iremos melhor em não empregar a palavra "metodologia" e aproveitando as ponderações de Andersen (2003)falar em "estratégia de análise”.

É que nosso trabalho utiliza-se, principalmente, da obra de Luhmann a qual, como sabido, muda o foco de suas perguntas de questões sobre o "quê" e "por quê" para questões sobre o “como" (LUHMANN, 2002). Ele tem mais, por assim dizer, preocupações epistemológicas do que ontológicas. Pode-se dizer que seu pensamento, pós-ontológico, "transita por formas de diferenças" e não por formas de ser, entes ou signos linguísticos. (SIMIONI, 2014, p. 595). Na ontologia, e seguimos no que iremos dizer as lições de Andersen (2003, p. XIII), usa-se um método para a observação de um objeto para produzir um "conhecimento verdadeiro" sobre ele. $\mathrm{Na}$ estratégia de análise parte-se da "observação de observações como observações" para questionar pressupostos, quebrar ontologias e obter um "conhecimento diferente" do que é dado pelo existente sistema de significados. Essa é a base sobre a qual nossa pesquisa repousa.

Assim é que os autores todos que aqui reunimos podem ser agrupados, no que se refere ao risco, e se desejamos o conforto de botá-los dentro de uma classificação, em um viés representacional do risco, ou seja, não entendem o risco como algo real mas como uma construção (KERMISH, 2012), e dentro dessa classificação, proposta por Kermisch, eles seriam ainda subclassificadoscomo pertencentes a uma concepção construtivista (BECK, 2011, 2016; LUHMANN, 2017) oua uma concepção quantitativa (KNIGHT, 2005).

Avançandoa questão metodológica (ou estratégica discursiva), podemos dizer que a análise dos conceitos nesse trabalho, desde o conceito de risco, passando pelo de contrato, de decisão etc,segue a protológica - expressão que retiramos de Clam (2006) -de Spencer-Brown (1979) tal como apreendida a partir de Luhmann. Isso implica um posicionamento dentro da teoria do conhecimento, ou seja, uma tomada de posição em um nível mais abstrato do que aquele no qual costuma operar o conhecimento do direito. Ou, falando sistemicamente, implica 
um posicionamento como observador de segunda (as vezes de terceira ou quarta) ordem.

Um observador de primeira ordem costuma enxergar apenas parte do problema que se propõe a resolver (trabalha com o objeto, com o ser). Essa constatação, elementar na teoria de Luhmann, é importante para a compreensão de nossa proposta.

Assim quando alguém se põe a trabalhar com o risco é apenas metade da questão, o lado interno da forma, que está indicando. Da mesma forma que, verbi gratia, o problema do bem implica, ainda que apenas latente, o problema do mal, como o pano de fundo sobre o qual se torna significativo, o problema do risco implica, mesmo que não se aperceba disso quem o maneja, o problema da segurança. Diz-se, nesse caso, que a forma do risco é risco/segurança.

Mas o esquema "risco/segurança" deve ser lido meramente como uma das possíveis construções, não como uma verdade essencial, decorrente da "natureza das coisas". Nessa base é que Luhmann (2017) realizou uma mudança nada sutil e com muitas consequências. Como contraconceito ao risco, no lugar da segurança, ele colocou o perigo.

Ora, era de causar espanto uma tal modificação, sobretudo para o direito e a burocracia, sistemas fanáticos por segurança. (LUHMANN, 2016, p.325). Se o contraconceitoao risco for o perigo isso implica que não existe uma opção segura para qualquer que seja o estado de coisas, há opções arriscadas ou perigosase, no mais, incerteza quanto ao futuro, apenas isso. Não devemos ter, portanto, aversões arriscadas ao risco (LUHMANN, 2006, p. 866), já que ele é incontornável.

O estudo pretende aplicar essa concepção sistêmica luhmannianado risco à teoria dos contratos. Cremos que seja possível considerar que o contrato permeia todas as relações sociais, fala-se hoje em pancontratualismoe fuga para o contrato ${ }^{3}$, no entendimento de que cada vez mais as relações sociais são contratualizadas. E isso vai além de aspectos meramente econômicos, como tradicionalmente se costuma pensar. De modo que o conceito de que o contrato é instrumento para a circulação de riquezas (ROPPO, 2009) é incompleto e não faz justiça a todas as suas potencialidades, por dardemasiada atenção ao sistema econômico e jurídicolimitando seu escopo.Daí as tentativas de trazer uma definição pós-moderna ao contrato, como veremos.

O que apresentamos aqui é uma forma de reler o contrato à luz do esquema risco/perigo que leve em conta sua totalidade significativa, que leve em conta o problema da decisão. Esse esquema trilha um caminho diverso do da tradição da contratualidade, sobretudo porque ele se volta para o futuro ao invés de se voltar para o passado.

É também um caminho diferente em relação a tradição do direito em geral porque opera a

${ }^{3}$ Expressões que tiramos de Schreiber (2018), segundo quem pancontratualismoé de Francesco Galgano e Fuga para o Contrato é o título da tese de Maria João Estorninho. 
desconstrução do princípio fundamental da segurança jurídica. Os juristas estão habituados a aceitar, inclusive, que a própria função do direito está vinculada a dar segurança(MELLO, 2010). Mas se partimos da pressuposição de que na sociedade orisco é ubíquo (RESCHER, 1983; MYTHEN, 2006) e que na versão luhmanniana, a alternativa ao risco passou a ser o perigo, a segurança aparece como uma ficção, uma ilusão, ou se quisermos falar na linguagem da teoria dos sistemas, uma autodescrição do sistema jurídico. Autodescrição que, todavia, descreve bastante imperfeitamente como as coisas acontecem.

Dessa forma a função do direito deve ser coisa diversa de prover segurança ou outro valor ${ }^{4}$. Por coerência com o referencial teórico dizemos, com Luhmann (1983, 2005), que a função do direito é a estabilização de expectativas normativasuma função que é cumprida, primordialmente, pela norma jurídica mas que também é cumprida pelo contrato.

\section{OBSERVAÇÕES DO RISCO NA SOCIEDADE}

O risco é um tema que atrai e por isso tem recebido muitas contribuições,de modo que a mera tentativa de organizar e classificar a imensa literatura a seu respeito já é um trabalho bastante difícil ao qual muitos se têm dedicado.

Uma interessante organização dessas abordagens, que já insinuamos,encontramos em CélineKermisch (2012) a qual remete às questões metodológicas esboçadas na introdução. Ela propõe que há concepções ontológicas e epistemológicas do risco. As primeiras o entendem como algo real e as segundas como algo virtual, motivo pelo qual são também chamadas de abordagens representacionais. A posição ontológica, temem Nicolas Rescher um de seus principais expoentes (KERMISCH, 2012), e vê o risco como algo distinto da percepção do risco. Rescher diz, com todas as letras e na contramão de nossa abordagem, que o risco é um problema ontológico e não epistemológico (RESCHER, 1983, p. 7).

Contrariamente, há a posiçãorepresentacionista do risco, quese subdivide entre uma concepção quantitativa e outra construtivista (ou qualitativa) ${ }^{5}$ (KERMISCH, 2012). A concepção quantitativa tem, desde suas origens, dominado a análise do risco (KERMISCH, 2012) e fornece para o tomador de decisões um instrumental valioso. Nela avulta a distinção knightiana entre risco e incerteza, a qual Luhmann $(2017$, p. 1) reconhece importância criticando, porém, sua

\footnotetext{
${ }^{4}$ Outro valor como a igualdade, por exemplo. Hespanha (2009) identifica funções para o direito que vão desde estabelecer a igualdade entre os cidadãos até a segurança jurídica, passando pela eficiência e instrumento de domínio de um grupo social.Uma variedade que chega a ser desconcertante.

${ }^{5}$ Em seu trabalho Kermish apresenta essas abordagens como complementares. As ideias de Knight sobre risco e incerteza não serão aprofundadas aqui. Assim, apesar de parecer um caminho interessante, renunciamos a uma tentativa de conciliação que leve à uma definição multidimensional do risco.
} 
dogmatização.Diz-se que,no campo econômico, a posição de Knight chega a ser uma unanimidade, ainda que apenas na fachada já que,malgrado todos se valham da díade knightiana, cada qual lhe atribui um sentido peculiar (PRADIER eSERRANO, 2000). A oposição risco e incerteza reflete no fundo a oposição entre teoria da probabilidade e teoria do conhecimento imperfeito (PRADIER eSERRANO, 2000). A distinção risco e insegurança, presente em Knight (2005) tem a ver com a possibilidade de cálculo (risco) ou não (incerteza).

De outro lado, a concepção construtivista, que não fala primordialmente em "percepção do risco", ou seja, de um risco exterior, tangível e localizável na natureza ou na cultura, mas sim em "representação do risco" (KERMISH, 2012), comporta autores muito diversos como Luhmann (sociologia dos riscos), Beck (teoria da sociedade do risco) ou Douglas (teoria culturalista do risco).

Assim é que encontramos nessa temática umvolumoso catálogode teorias. Gabe Mythen aponta quatro paradigmas: o antropológico, o da psicologia social, a abordagem governamental (Foucault), além da perspectiva da sociedade do riscode Beck (MYTHEN, 2004, p.9). Deborah Lupton entende haver três principais perspectivas teóricas em sociologia(DENNEY, 2005, p. 13), a da sociedade do risco, a cultural/simbólica e a governamental (LUPTON, 2006, p.11). Mendes (2015), a seu turno, destaca a ausência em Lupton da teoria da escolha racional de OrtwinRenn, da teoria crítica de Habermas e da teoria dos sistemas de Luhmann(MENDES,2015. p. 22).E, decerto, outras poderiam ser elucubradas como faz Denney (2005, p.13-16)ao arrolar seis tipos ideais de abordagens, as posições individualista, culturalista, fenomenológica, da sociedade do risco, a pós-moderna e a regulatória.

Essa listagem,provavelmente não exaustivamas exagerada,ilustra algumas contribuições ao tema e dá a noção da dificuldade de alcançar um consenso sobre o significado do risco (DENNEY, 2005). Desse rol, chamamosa atenção para a perspectiva teórica da Sociedade do Risco deUlrich Beck, em razão de sua influência, já que se costuma afirmar que nenhum autor foi, nesse campo, mais influente que ele (MYTHEN, 2004, p. 28), influência que contribuiu para que sua teoria fosse uma das mais debatidas (MENDES, 2015, p. 23).

As ideias de Beck podemos resumi-las, para nosso propósito, em duas teses, a tese do risco e o teorema da individualização (LASH, 2002, VII). A primeira toma o risco como o traço definidor da sociedade (BECK, 2011) e faz do risco, portanto,a feição essencial de nossa sociedade (ESPOSITO, 2011, p.19). Essa "Sociedade do Risco" para a qual se encaminhava a humanidade já na década de 80 do século XX, caracteriza-se pela globalidade do risco, no sentido de que ele não respeita as fronteiras dos Estados e também pela sua universalidade pois atinge todas as classes sociais. 
Para o desenvolvimento dessa tese Beck se vale do contraste com a sociedade industrial.Distingue entre a modernização da sociedade tradicional e a modernização da modernidade, também chamada de segunda modernidade ou modernização reflexiva. Malgrado reconheça que a existência humana sempre tenha estado sujeita à ameaça e à insegurança (BECK, 2016, p. 22) e o risco não seja uma invenção moderna (BECK, 2016, p. 25), foi na modernidadeque as "ameaças incalculáveis" foram transformadas em "riscos calculáveis" através de sistemas de seguros (BECK, 2016, 209). Reddy (2006, p. 237) diria que os modernos eliminaram a indeterminação genuína através do mito da calculabilidade.

O certo é que a sociedade do risco surge quando os riscos criados já não podem ser mais contidos ou contornados através do cálculo (BECK, 2016, 209) e dos seguros. Esse cálculo seria possível a partir do desenvolvimento da probabilidade, a ciência que cuida do aleatório e que se tornou uma útil ferramenta para a tomada de decisões.

O que o seguro consegue realizar é a transformação de perigos difusos em riscos econômicos (ESPOSITO, 2011, p.37), o que quer dizer que o perigo não se torna segurança com o uso do seguro,ele se transforma em risco (ESPOSITO, 2011, p. 38), é a monetarização do risco, que faz do sistema econômico o último recurso do risco que vem de todas as direções (LUHMANN, 2017, 175).

Como se vê, havia na modernidade um otimismo exagerado no poder presciente da razão e da ciência, o qual, no século XX, começou a ruir (ROCHA e AZEVEDO, 2012). Acreditar na segurança de um modo geral, e na segurança jurídica especificamente, não deixa de ser um modo de ser desse mesmo otimismo. Atualmente, e no direito de maneira mais aguda, subsisteentretanto a crença ("fanática”, na hipérbole luhmanniana) na segurança. Com isso podemos reconhecer que as teorias do risco, as que creem bem como as que descreem na segurança, ainda disputam espaço.

Mesmo para autores que trabalham no esquema risco/segurança ficou claro, porém, isto: que a insegurança era insuperável através de mais conhecimento e que na verdade o oposto, o seu aumento, resultava dos avanços no conhecimento, (BECK, 2016, 24), de modo que a evolução da ciência falhou em prover um clima social mais seguro (MYTHEN, 2004, p. 3). A busca de informação aumenta a incerteza (ESPOSITO, 2011, p. 19), o que não isenta o decisor de buscar informações e levá-las em conta, mas ciente de que o futuro não lhe será revelado por essa pesquisa. As organizações, por exemplo, precisam decidir por si mesmas, mesmo possuindo apenas informações insuficientes (LUHMANN, 2010, p. 47).

Ainda assim é possível vislumbrar um aspecto positivo na opacidade do futuro. Esposito afirma que a ignorância é um recurso (2011, p. 27), que a incerteza é um recurso (2011, p. 11). 
Smithson (1989, p. 9) entende que a incerteza ocupa uma especial posição como um tipo de ignorância gerenciável. Segundo ele, não vai longe o tempo em que a maneira de se lidar com a ignorância eratentando eliminá-la ou absorvê-la, mas considerando sua irredutibilidade, outra maneira de tratá-la emergiu, e consiste em buscar entendê-la e tolerar sua existência, sendo possível mesmo usá-la, em algumas das suas formas, (SMITHSON, 1989, p. VIII) como no caso da incerteza. Então é possível lucrar, tirar vantagem desse estado de coisas, desde que haja disposição para assumir riscos.

Vive-se assim, na chamada segunda modernidade, umasituação paradoxal, pois no momento em que as pessoas passam a ter vidas mais seguras, com maior expectativa de vida, a sensação de segurança diminui. Mythen (2004, p. 3) especula que talvez isso seja porque as informações sobre os riscos estejam mais disponíveis em virtude da difusão dos meios de comunicação de massa. Esse ponto faz sentido se aceitamos, sempre em uma abordagem representacional, que o risco possui uma "realidade", um modo de ser peculiar, ele é uma encenação (BECK, 2016) de algo que pode vir a ser mas que no momento ainda não é pois se fosse não seria risco, seria uma catástrofe.

No que concerne ao teorema da individualização, a nosso ver, diferentemente da tese do risco, ele é elaborado em comparação direta com a tradição (o mundo feudal). Enquanto a sociedade do risco surge na segunda modernidade que é a modernização da sociedade industrial (ou modernização reflexiva) a individualização, quelança sobre os indivíduos o fardo da responsabilidade pelo que lhes sucede, desponta no horizonte desde a sociedade industrial. $\mathrm{O}$ fracasso pessoal (desemprego, reprovação em um exame, divórcio etc) não é mais um golpe do destino mas o resultado das decisões tomadas (BECK, 2011, p. 200). Ora, o alheamento do indivíduo em relação as suas ações, e a consequente atribuição dos males sobrevindos a algo transcendente era muito mais distinto na sociedade medieval, estratificada e rígida, do que na "primeira modernidade", onde se começa a ver uma relação de causa e efeito entre os acontecimentos biográficos e as decisões.

Esse é o delineamento geral que pretendíamos realizar sobre o pensamento de Beck. Suas ideias, observadas a partir da teoria dos sistemas, ou seja, com um deslocamento para a observação de segunda ordem, estão involucradas no esquema risco/segurança, essa é a forma do risco em Beck.

Bastante diversa é a posição de Luhmann com a forma risco/perigo. Antes de cuidarmos do esquemaluhmanniano, todavia, vale registrar que Beck busca também distinguir o risco do perigo, sobretudo em seu "Sociedade do Risco Mundial" (2016), quase em um sentido luhmanniano: “pode acontecer a mesma coisa ser considerada por uns como 'risco' e por outros 
um "perigo"” (BECK, 2016, p. 260), mas não o faz de forma conceitualmente rigorosa, "com a desejada nitidez", como Luhmann diz (2006, p.865), pois não usa do cálculo das formas de Spencer-Brown.Ele entende, realmente, que os riscos decorrem de decisões, que eles “pressupõem uma possibilidade de decisão" (BECK, 2016, p. 208), mas ao dizer que os riscos seriam a resultante da transformação de incertezas e perigos em decisões (BECK, 2016, p. 208) isso parece muito distante de Luhmann, parece mesmo inverter o modo como esse último elabora sua teoria, pois as decisões é que fazem dos perigos, riscos. E a incerteza permanece, renitente. Em verdade, do ponto de vista da teoria dos sistemas,a assertiva "transformação de incertezas e perigos em decisões" parece ininteligível.

Há, portanto,uma diferença inconciliável entre o tratamento de Beck e o de Luhmann sobre o risco. Não se pode dizer que se trata de dois teóricos da sociedade do risco, como faz Ost (1999, p. 271), embora talvez seja possível concordar que eles convirjam no ponto em que o perigo venha do "exterior" (do ambiente) enquanto o risco é um "efeito perverso" de nossas próprias decisões (OST, 1999, 271). Mas isso somente se não perdermos o foco de que em Beck o risco se opõe à ideia de segurança e não ao perigo como em Luhmann (BUSANELLO, 2011, p. 143). Esse ponto parece ter ficado claro.

Luhmann discorda que um aspecto parcial da sociedade (risco ou informação, "sociedade da informação", por exemplo) pudesse bastar para caracterizá-la ${ }^{6}$. Ele dizia que a expressão "Sociedade do Risco", bem como a conhecida "Sociedade da Informação", era um slogan, que destacava somente um aspecto espetacular ou propagandístico da sociedade (LUHMANN, 2006, 862), parcial e inapto a explicar o todo. Ele alertava, inclusive, (LUHMANN, 2006, 865) que para a criação do slogan "sociedade do risco" aproveitava-se da falta de nitidez do conceito de risco e da falta de distinções claras.

Parece-nos, ademais, que o próprio título do livro de Beck "Sociedade do Risco Mundial: Em busca da segurança perdida", o qual ele próprio afirma ter sido escrito como reação à Luhmann(BECK, 2016, p. 11) confirma o que vimos dizendo: Beck acreditava na possibilidade da segurança, esse é o seu contraconceito ao risco, é contra a segurança que fala o risco em Beck (SIMIONI, 2016). E se "um conceito só pode ser usado quando ele torna visível aquilo que ele exclui" (LUHMANN, 2013, 17-18), ou bem Beck se vale da segurança como valor excluído, segundo nos parece, ou ele oscila entre segurança, perigo ou outros valores intermediários, como às vezes também deixa transparecer, de modo inconsistente, e nesse caso a construção de sua teoria vacila do ponto de vista da técnica.

Diversamente,Luhmannfoi cuidadoso nesse quesito e adotou, como antecipamos, o perigo

${ }^{6}$ Por isso ele não se acomoda dentro do rótulo de teórico da "sociedade do risco" como alguns pretendem. 
como contraconceito ao risco.A "forma do risco" refere-se ao esquemade observaçãoutilizado (i.e., quais diferenças são manejadas)e sabemos que podeoscilarentre risco e incerteza (KNIGHT, 2005), entre risco e segurança (BECK, 2011, 2016) ou entre risco e perigo (LUHMANN, 2017).

Luhmann realizou essa alteração utilizando-se da observação de segunda ordem (LUHMANN, 2017, p. 14). Para ele, riscos são aspectos da observação de decisões (LUHMANN, 2017, p. 104), e a distinção entre o que seja um risco ou o que seja um perigo é somente uma questão de atribuição: se atribuímos a possível perda "futura" (com o perdão da redundância) à decisão então falamos em risco, se a atribuímos ao ambiente então falamos em perigo (LUHMANN, 2017, p. 21-22).Mas no final das contas, "ontologicamente" pensando, eles são a mesma coisa. O perigo não é uma condição prévia que permita o risco surgir nem viceversa. A incerteza é permanente, não se sabe se haverá ou não a perda no futuro (seja com a atribuição à decisão - risco - ou ao ambiente - perigo), como se vê.

Então, a sociedade - que não deve ser adjetivada de "sociedade do risco" - deve, contudo, enfrentar o problema do risco, que ao final acaba por se revelar um problema de decisão. Para fazer a leitura do risco e do contrato nesse estudo partimos do aspecto decisório que se encontra envolvido tanto no risco quanto no contrato, bem como no direito de uma maneira geral. Assim como o risco é um aspecto de uma observação de decisões o contrato, enquanto espécie importante de decisão jurídica é uma maneira de transformar perigos em riscos (econômicos).

O problema da decisão se encontra atrelado à própria origem da teoria dos sistemas, quefoi formada em conexão com questões ligadas aos processos de tomada de decisão, os quais, por sua vez, são voltados à noção de tempo (ROCHA, 2012, p.21). Assim, Rocha pode afirmar que decidir é participar do processo de produção do futuro e que decidir é produzir Tempo, além de, na teoria dos sistemas, produzir uma diferença. Perguntar o que é o tempo, contudo, permanece uma questão vazia, o que conta é saber como ele funciona (ESPOSITO, 2011, p. 20) especialmente no caso da tomada de decisões.

O problema da decisão está na base da ciência dogmática do direito. Ferraz Jr.(2015, p. 82) ensina que não importa qual seja o objeto da dogmática, ela sempre envolve um problema de decidibilidade,e Simioni(2014, p. 24)afirma que a decisão jurídica se constitui no núcleo prático das preocupações teóricas do direito e que aquilo que outrora se conhecia por "metodologia jurídica" hoje se convolou em uma "teoria da decisão".

Todavia, uma teoria elaborada da decisão excede o marco de investigação do direito (LUHMANN, 2005, 219). O fundamental será ter em conta, e essa ideia pode parecer surpreendente para muitos juristas, que o problema da decisão jurídica não está em uma questão 
de método, ou de controle metodológico do arbítrio do decisor (SIMIONI, 2017, p. 276), como se costuma imaginar, mas na dimensão organizacional. É como os dois lados de uma mesma forma que organização e decisão se autoconstituem (SIMIONI, 2017). As organizações enquanto sistemas autopoiéticos são estruturadas para permitir, possibilitar, a tomada de decisões. As decisões a seu turno compõem as estruturas da organização. É um processo recursivo. E se o contrato é uma decisão, podemos imaginar a importância que assume como parte significativa das decisões que conformam as organizações.

A decisão jurídica é um gênero cuja espécie mais saliente é a decisão judicial. Simioni (2017, p. 265) define a decisão judicial pelo local em que é tomada, ou seja, o judiciário, a organização central do sistema jurídico. Mas deveras é de se supor (SIMIONI, 2017, 266) que apenas uma ínfima parcela das decisões jurídicas devam ser tomadas dentro do judiciário, pois o que define uma decisão como jurídica, ou como pertencente a este ou aquele sistema, é o seu código não o lugar onde ela acontece. Assim é que em todos os contextos da sociedade podemos observar decisões jurídicas, não apenas na organização central (tribunais) do sistema do direito (SIMIONI, 2014, p. 712). Porque decisões jurídicas são as que se tomam levando em conta o código do sistema do direito "direito/não direito" (lícito/ilícito, justo/injusto).

Qualquer decisão que se valha desse código é uma decisão jurídica não importa onde aconteça. Assim, os exemplos podem se multiplicar. Perlingieri(2007,p. 90) tem razão quando diz que entrar no carro e dirigir alguns metros já é um ato juridicamente relevante. E se ao fazer seu trajeto a pessoa decide obedecer aos sinais de trânsito essa decisão será uma decisão jurídica, pois baseada no código direito/não direito. O mesmo raciocínio vale para o contrato.

Não há porque vacilar em reconhecer que o contrato é uma decisão. Como acoplamento estrutural entre economia e direito (LUHMANN, 2005) será tanto decisão jurídica quanto econômica. Deve-se pensar, então, qual o significado dessa constatação.Mas vejamos um pouco do tratamento da contratualidade na doutrina tradicional.

\section{A CONTRATUALIDADE MODERNA E A FUNÇÃO DO DIREITO}

O contrato como o conhecemos é um artefato jurídico que foi trabalhado e aperfeiçoado dentro do contexto moderno que se seguiu à revolução francesa e ao qual se atribui um papel de destaque na consolidação da vitória da burguesia.

Na passagem do feudalismo para o capitalismo o contrato teria funcionado como "mola propulsora da revolução burguesa” (TIGAR e LEVY, 1978, p. 211). Segundo a Lei de Maine (ROPPO, 2009) a modernidade se caracteriza pela mudança de enfoque do status para o contrato. 
As relações jurídicas entre as pessoas eram mediadas pela propriedade no feudalismo (servidão, senhor feudal) enquanto no capitalismo esse papel passou para o contrato (TIGAR e LEVY, 1978, p. 211). Para Luhmann(2005, p. 321), na Idade Média, a política e a economia dependiam do recurso à propriedade da terra mas esse estado de coisas sofre um acelerado processo de erosão ainda na Idade Média em virtude do rápido desenvolvimento da economia de dinheiro. A verdadeira riqueza deixa de ser a propriedade de terras para ser a titularidade de papeis de crédito e essa desmaterialização da riqueza dá novas possibilidades ao comércio, (NUNES, 2017, p. 27).A vitória da burguesia na Revolução Francesa permitiu conciliar a liberdade com a transferência de terras da nobreza e do clero para essa então ascendente classe (ROPPO, 2009).

Dessa forma a moderna teoria do contrato coincide geográfica e temporalmente com o capitalismo nascente (ROPPO, 2009, p. 25).O marco jurídico é o CodeNapoleon, que trazia uma ideia de autonomia da vontade, uma ideia que não se sabe se é ingênua ou engenhosa (COELHO, 1994, p. 4), em que os homens são livres e capazes, igualmente, para realizar suas convenções, praticar os atos da vida civil. Era dentro desse paradigma de igualdade formal que o Código de Napoleão protegia o interesse dos fortes e desconhecia o interesse dos débeis (CARVALHO, 1981, p. 71). Na Alemanha, a pandectística também servia ao mesmo propósito (CARVALHO, 1981) e elaborou uma categoria ainda mais abstrata que a de contrato, o negócio jurídico, “formidável instrumento ideológico", um dos pontos mais altos do direito burguês (ROPPO, 2009, p. 50), que podia ser utilizado para tutelar melhor determinados interesses não econômicos (ROPPO, 2009, p. 29).

Chama atenção que, contraditoriamente, ao contrato se assinale uma vocação, frequentemente frustrada, para realizar o princípio da igualdade. (SCHREIBER, 2018). Luhmann nota a assimetria da questão da igualdade nos institutos fundamentais do direito privado: propriedade e contrato. Homens nascem iguais e vão se desigualando à medida em que a sociedade evolui. Mas enquanto para a propriedade se reconheça a desigualdade entre as pessoas quando o assunto é o contrato se mantém a "igualdade para a liberdade de uma decisão volitiva" (LUHMANN, 2005, p. 322,323). É a igualdade formal, perante a lei, a qual Anatole France traduz magistralmente: "la majesteuse égalité des lois, qui interdit au riche comme au pauvre de coucher sous les ponts, de mendier dans les rues et de voler du pain » ${ }^{7}$

O método da dogmática, que permitiu alcançar tanto o conceito de contrato quanto o de negócio jurídico, consiste em dar primeiro uma definição para depois seguir com a classificação conforme gêneros e espécies (AZEVEDO, 2004, p.39). Luhmann chama isso 


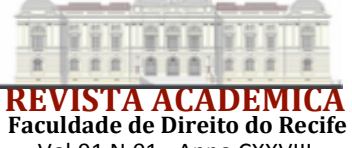

Faculdade de Direito do Recife

degenostechnique(LUHMANN, 1999) e dela se afasta deliberadamente ao afirmar que não vê o Direito como um cosmos composto por essências organizadas a partir de gêneros e espécies (LUHMANN, 2005, p. 94). Aparta-se da tradicional visão hierárquica do Direito etrabalha com a protológica de Spencer-Brown.

O sucesso da dogmáticaresultou emque a teoria dos contratos passou a ser considerada uma das partes mais perfeitas e estáveis do direito civil (DANTAS, 1953, p. 13). A racionalidade que se atribui a contratualidade lhe permite, nessa visão assaz difundida, que vem sendo estabelecida desde os jusnaturalistas holandeses e alemães no séc. XVII (ROPPO, 2009, p. 9),uma transcendência que a tornaria apta a reger qualquer sociedade humana, em qualquer época e em qualquer lugar. (DANTAS, 1953, p.13).

Nessa visão o contrato é tido por uma categoria racional, a-histórica, usualmente definido como instrumento de circulação de riquezas (ROPPO, 2009, p. 10), sob um pano de fundo onde se reconhece que existem ao menos duas "realidades" distintas, uma econômica e outra jurídica a qual não faz senão revestir de legalidade a primeira (ROPPO, 2009, p. 9). Existe o contratoconceito jurídico e o contrato-operação econômica. Ora, enquanto conceito jurídico, o contrato serve para sintetizar a série de princípios e regras de direito que lhe compõem a disciplina (ROPPO, 2009, p. 7), o que se chama de regime jurídico da matéria contratual, mas nunca se deve perder de vista que o contrato-conceito jurídico, embora possua autonomia (ROPPO, 2009 p. 9 e 24), é instrumental, subserviente, em relação ao contrato-operação econômica (ROPPO, 2009, 9-10).

O Código Civil Italiano, que ao contrário do nosso definiu o contrato, o fez salientando o aspecto econômico: "ilcontratto è l'accordodidue o più parti per costituire, regolare ou estingueretra loro unrapportogiuridicopatrimoniale" (art. 1321), ou em vernáculo "o contrato é o acordo entre duas ou mais partes para constituir, regular ou extinguir entre si uma relação jurídica patrimonial”. Ora, Roppoparte dessa definição (2009, p. 11) para estabelecer que "onde não há operação econômica não pode haver também contrato" e essa conclusão radica no adjetivo final "patrimonial”. A função do contrato é transferir a propriedade, tradução jurídica da riqueza, e onde houver circulação de riqueza, dado objetivo, haverá operação econômica (ROPPO, 2009, p. 13) que independe de considerações de ordem subjetiva sobre que valores moveram o sujeito a contratar, que podem ter sido considerações não utilitaristas ou não especulativas sem desfigurar a operação econômica.

Vislumbramos nessa ênfase ao aspecto econômico ecos marxistas, que designava ao sistema econômico o papel de uma infraestrutura dominante sobre os demais sistemas sociais (direito, política etc). Malgrado a genialidade de Marx, nos termos sistêmicos, que nos 
interessam, esse modelo não se sustenta. Moeller (2012, p. 225) entende haver duas falhas básicas na análise de Marx, uma ligada à não distinção entre o que pertence à economia enquanto sistema social e o que pertence ao seu ambientee ainda, em segundo lugar, o não ultrapassar a ideia de uma hierarquia dominante entre os diferentes domínios sistêmicos.

A teoria dos sistemas, avessa às hierarquias, constrói um modelo acêntrico de sociedade, onde cada sistema é seu próprio centro e tem como ambiente todos os demais sistemas. Dessa maneira, qualquer teoria que busque identificar o primado de dado sistema social não pode ser acolhida em seus domínios.

Hoje, entretanto, circula a ideia de que o contrato permeia todos os aspectos da socialidade, o que se pode bem exprimir com a palavra pancontratualismo ${ }^{8}$ (SCHREIBER, 2018) e com a expressão, "fuga para o direito privado"” (SCHREIBER, 2018). Grosso modo, com a primeira se procura designar a "contratualização" das relações privadas estendendo-se o contrato a relações antes governadas por outras áreas, como direito de família, sucessões etc. Com a segunda refere-se a extensão do mesmo fenômeno no direito público, ou seja, no direito administrativo, processual (e.g. negócio jurídico processual) etc.

Pode ser quetal novidadeafinal sejamera reminiscência de alguma coisa que se perdeu no influxo de mais de 200 anos do pensamento jurídico que reiteradamente traduziu o universo contratual em termos econômicos.O retorno de uma ideia esquecida traz um quê de novo, malgrado não seja algo em si inédito. Teubner(2005, p. 273)o demonstra a partir do afresco de Ambrogio Lorenzetti, conhecido como Allegorieedeffettidelbuono governo e cativo governo in cittàed in campagna.

A partir desse afresco o autor assevera que não há um único mas múltiplos mundos contratuais e mais, que a coordenação dos sistemas sociais não acontece por meio de relações hierárquicas - e ressaltamos: não pelo primado da economia - mas por meio de relações contratuais heterárquicas (TEUBNER, 2005, p. 278). Ora, trata-se, o afresco de Lorenzetti, de um retrato utópico de uma sociedade altamente integrada (TEUBNER, p. 275).

Parece-nos claro que se o contrato for considerado apenas em seu aspecto econômicojurídico a sua compreensão fica prejudicada. Se de um lado o momento econômico não é eliminável (PERLINGIERI, 2007, p. 33), de outro o direito não pode se cingir apenas ao momento econômico (PERLINGIERI, 2007, p. 64).

Quando analisamos uma definição pós-moderna de contrato, como a de Paulo Nalin (2005) vemos que ela acrescenta ao lado da produção de efeitos patrimoniais os efeitos

${ }^{8}$ Expressão de Francesco Galgano que encontramos em Schreiber(2018).

${ }^{9}$ Título da tese de doutorado de Maria João Estorninho. 
existenciais, além de fixar que referidos efeitos se produzem não somente entre as partes mas também entre terceiros ${ }^{10}$. Essa abordagem, que relê o Código Civil à luz da Constituição Federal, distingue aspectos patrimoniais e existenciais, e reconhece ao contrato vocação para cuidar desses últimos tanto quanto dos primeiros. O "pós" da definição está no aspecto existencial em confronto com patrimonial,além de nos "efeitos extra partes".

Teubner (2005, p. 272), e na mesma linha Lopes Jr. (2012, p. 149), propõe que o contrato seja entendido como intertextualidade, e na esteira de Derrida (TEUBNER, 2005, p. 271), que o liame obrigacional não acontece entre duas pessoas, a que dá e a que recebe, mas entre dois textos, dois discursos. Contraria, como se percebe, a definição corrente, presente no Código Italiano que citamos acima, e na qual o contrato constitui uma relação entre as partes. Ao deixar de "ser" uma transação econômica entre dois agentes o contrato passa a ser um "espaço de compatibilidade entre vários projetos discursivos" (TEUBNER, 2005, p. 272). Ora, para que isso seja possível uma das condições é abandonar a definição do contrato como a formalização jurídica de uma transação econômica, já que essa definição exclui de partida "importantes dimensões políticas e sociais da relação contratual", além de serem de pouca utilidade (TEUBNER, 2005, p. 272).

Esse aspecto multidimensional do contrato é que entendemos mais condizente com uma descrição acurada de sua participação na função geral do direito de estabilizar expectativas normativas. Ao mesmo tempo em que não se nega sua função de possibilitar as trocas no campo econômico permite atender a outros objetivos pretendidos pelas partes em obter saúde, educação, informação, segurança etc, os quais a despeito de terem um fundo econômico revelam fundamentalmente uma questão existencial, de projeto de vida.

ParaLuhmann (2005), como dissemos, o direito deve ter apenas uma função, estabilizar expectativas normativas (LUHMANN, 1983, 2005). Expectativas podem ser cognitivas ou normativas, eo que as distingue é que enquanto as primeiras são revistas em caso de frustração (LUHMANN, 1983, p. 56), o que leva à aprendizagem, i.e. adaptação à realidade, as segundas são mantidas ainda que contrafaticamente, o que, em linguagem mais familiar aos juristas, se denomina “dever ser” (LUHMANN, 1983, 57).

Acontece que em um mundo complexo e contingente se faz necessária a existência de estruturas que têm a propriedade de possuir uma constância relativa (LUHMANN, 1983, 53). Que permita referir os diversos passos de uma seleção um ao outro produzindo o obscurecimento de alternativas. (LUHMANN, 1983, 54). O Direito possibilita saber quais expectativas

\footnotetext{
10 “a relação jurídica subjetiva, nucleada na solidariedade constitucional, destinada à produção de efeitos jurídicos existenciais e patrimoniais, não só entre os titulares subjetivos da relação, como também perante terceiros" (Nalin, 2005, p. 255).
} 


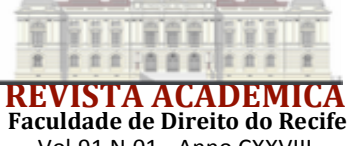

(1)

normativas possuem e quais não possuem resguardo social (LUHMANN, 2005, p. 91). E a sua função geral de estabilização de expectativas é cumprida primariamente pela norma (LUHMANN, 2005, p. 94), mas acreditamos que dela participam também outros institutos jurídicos, dentre os quais o contrato. O direito funciona como um sistema imunológico dentro da sociedade, através da antecipação de conflitos (LUHMANN, 2016, p. 425). O direito não possui o poder de impedir que suas regras sejam violadas e que eventos e ações indesejadas aconteçam, mas ele assegura a manutenção da expectativa mesmo contrafaticamente.

\section{DECISÃO E CONTRATO NA TEORIA DOS SISTEMAS}

Averbado que o contrato também realiza, como outros institutos jurídicos,a função do direito de manutenção de expectativas normativas, deve-se acrescentar que, na teoria dos sistemas, ao contrato seatribuiainda a função de acoplamento estrutural entre a economia e o direito (LUHMANN, 2005). Essa posição de acoplamento estrutural, porém, nãoespelhade maneira alguma aquela afirmação do contrato-operação econômica e contrato-conceito jurídico.

O sentido de acoplamento estrutural é bem diverso. Enquanto na doutrina tradicional, por exemplo em Roppo (2009), se vê uma realidade econômica condicionando a outra, jurídica, em Luhmann a ideia de acoplamento estrutural apenas quer dizer que um mesmo evento (comunicação), como o contrato, pode ser elemento de mais de um sistema social, sem com isso anular a sua diferenciação (BARALDI, CORSI, ESPOSITO, 1996, p. 31-33).Um mesmo evento (contrato) pode ser observado de maneiras diversas,pois podemos transitar, como observadores externos, por diversos sistemas (SIMIONI, 2014, p. 712).Cada sistema funcional da sociedade pode ser irritado pelo mesmo evento, que será nele processado, em seu próprio tempo, como informação. Basta pensar no exemplo do dízimo ofertado em uma igreja, que é ao mesmo tempo uma operação do sistema econômico e do sistema religioso (BARALDI, CORSI, ESPOSITO, 1996, p. 33).

A decisão na teoria dos sistemas desempenha um papel destacado no âmbito do estudo das organizações.As organizações merecem atenção por várias razões. Estão em toda parte e passamos significativa parte do nosso tempo dentro delas, por isso são importantes para explicar o comportamento humano, uma vez que representampara a maioria das pessoas a maior parte de seu ambiente. (MARCH e SIMON, 1993, p. 21). As organizações permitem reduzir a complexidade decisional, ao vincular as operações (decisões) umas às outras. Organização e decisão compõem os dois lados de uma forma (LUHMANN, 2010). No que se refere às organizações, se o contrato é realmente uma decisão, boa parte da autopoiese das organizações 
será realizada através dele, afinal, a autopoiese dos sistemas se realiza no nível das operações (LUHMANN, 2010, p. 73). A decisão gera uma diferença entre passado e futuro e garante o fechamento operacional do sistema na medida em que cada decisão se torna a premissa para decisões ulteriores (LUHMANN, 2010, p. 89).

Outro ponto diz respeito à decisão jurídica, que é a operação nuclear do sistema jurídico (SIMIONI, 2017, p. 265). A metodologia jurídica, ou hoje em dia, teoria da decisão jurídica (SIMIONI, 2014), na teoria dos sistemas enxerga a decisão como uma operação que integra uma dinâmica recursiva juntamente com a argumentação e interpretação jurídicas (SIMIONI, 2014).Se é certo que toda organização precisa decidir, nos tribunais essa necessidade atinge um ponto crítico diante da proibição do non liquet, ou seja, de um juiz não poder não julgar o caso (deixar de decidi-lo) alegando simplesmente que "não está claro" o direito aplicável(LUHMANN, 2005, 222). Diante do fato de ser forçosa uma decisão,à pergunta, o que fazem os tribunais?, responde-se “decidem”. (LUHMANN, 2005, 119). A decisão nos tribunais, portanto, possui essa diferença com relação à decisão no âmbito de outras organizações: enquanto os contratos não devem ser necessariamente firmados, nem as leis devem ser necessariamente promulgadas, os tribunais, a seu turno, devem decidir, necessariamente, em todo caso que se apresente (LUHMANN, 2005, 221).

Como se nota,estudar as decisões possibilita compreender desde a dinâmica dos tribunais (enquanto organizações) até a função dos contratos. Certamente os contratos, muitas vezes, acabam indo parar nos tribunais, que se ocupam crescentemente de interpretá-los, interpretando inclusive a vontade dos contratantes (LUHMANN, 2005, 217), mas seu lugar usual são as organizações empresariais e as interações entre as pessoas.

Então o contrato vai gerar, por ser decisão, uma diferença entre o passado e o futuro. $\mathrm{O}$ futuro, como sabemos, é incerto em relação à possibilidade de perda (LUHMANN, 2017, 21-22). Desse modo, os contratantes assumem um risco e submetem o ambiente (do sistema) ao perigo. O mesmo "evento", assinatura do contrato, será tomado como risco para uns e como perigo para outros. Se os temores se realizarem, se houver um eventusdamni (para usar do jargãoda responsabilidade civil), na concepção representacional do risco, isso não será mais nem risco nem perigo,mas o infortúnio, a desgraça, a tragédia. A hipótese do evento danoso que pode se seguir ao evento contrato, sua "encenação" (BECK, 2011, 2016), é que pode ser risco ou perigo.Nesse sentido é que contratos de seguro visam resguardar o segurado dos possíveis prejuízos.

Porém, se por um lado, quem assume o risco ao firmar um contrato vê seu aspecto positivo, vantagens que fazem valer a pena corrê-lo, de outro, quem não contratou só pode 
realmente enxergar desvantagens, pois o contrato, feito como é no interesse dos contratantes, em regra, não costuma beneficiar a terceiros, senão indiretamente, vez ou outra.O que, aliás,se exprime no princípio da relatividade dos contratos.

Desenha-se, como se nota,uma situação conflitiva entre os tomadores de decisão (contratantes) e os afetados pela decisão (terceiros). Issonão passou despercebidopela doutrina jurídica quesacou outro princípio, o da função social do contrato, reconhecendo que ele provoca efeitos externos à relação.Ou seja, afeta o ambiente (no sentido da teoria dos sistemas) bem como o sistema (de interação, organizacional etc) onde é pactuado. Daí que os efeitos negativos externos do contrato devam ser todos levados em conta e a função social funciona ao modo de um "contraprincípio" ao princípio da relatividade dos pactos.

Outra questão, referente aos riscos nos contratos,considera o momento pré-contratual, a (im)possibilidade de contratar. O exercício da liberdade contratual, expresso no princípio da autonomia privada, ou iniciativa privada como prefere Perlingieri (2007, p. 18), é uma oportunidade para a pessoaprojetar seu futuro. Como mostramos, com Beck (2011), na sociedade moderna os reveses na vida do ser humano são imputados às suas decisões.

Entra em cena, contudo, a desigualdade de oportunidades para firmar contratos, o que compromete de rebote a liberdade de firmá-los. Nem todos podem contratar planos de saúde ou seguros por exemplo. De Giorgi (2008) dá um exemplo dramático no caso americano de Nova Orleans quando da passagem do furacão Katrina, quando o governo resolveu delegar,para tragédias futuras, o resgate à iniciativa privada. Argumenta-se que haverá mais eficiência quando na verdade haverá mais exclusão.

Ora o risco, tradicionalmente, se considera como problema externo ao contrato, que não tem a ver com sua especificidade decisória, mas que poderia ser um problema econômico, político, administrativo, ambiental etc, ou seja, sempre externo ao direito. (LUZ e SIMIONI, 2016, 325). Nosso entendimento é o de que o risco seja primariamente um problema da decisão jurídica contratual, sujeito às injunções do ambiente econômico, político etc, as quais nesse caso poderão ser tomadas como risco ou como perigo a depender da atribuição que se faça.

\section{CONSIDERAÇÕES FINAIS}

Apresentamos algumas teorias sobre o risco, cada qual com seu peculiar esquema de distinções, com destaque para Knight (2005), Beck (2011, 2016) e Luhmann (2017) e as respectivas díades, risco/incerteza, risco/segurança e risco/perigo. Nosso interesse permaneceu em Luhmann, que distingue o risco em confronto ao perigo e possibilita afirmar que a segurança 
jurídica (em verdade, a segurança tout court) é ilusória, nada obstante a afirmação oposta difundida nos manuais de direito.

Diz-se que a popularidade do risco reside predominantemente em sua urgência com o futuro. Ao passo que formulações tais como sociedade industrial, capitalista ou moderna, incluindo as versões com o prefixo "pós" (sociedade pós-industrial, pós-capitalista ou pósmoderna) definem o presente com o olhar para o passado, a sociedade do risco o define com o olhar para o futuro (ESPOSITO, 2011, p. 3 e 4). Mas é claro, não esqueçamos, "sociedade do risco", para Luhmann (2006) é só um slogan, embora muito difundido.

O estudo propôs a leitura do risco nos contratos a partir do entendimento de que o contrato é uma decisão jurídica, que produz uma diferença entre passado e futuro. E mais, que há múltiplos mundos contratuais, multiplicidade que é adequada a uma proposta de leitura construtivista da contratualidade.

A proposta do contrato como decisão é voltada para o futuro porque este é baseado em decisões. As decisões modificam o tempo todo como o futuro será embora isso não queria dizer que possamos deveras conhecê-lo, unicamentetemos a certeza de que o que há de vir estará vinculado ao que se decide hic et nunc, no presente. A única certeza é que decisões ocorrem sob condições de incerteza (SIMIONI, 2012), o que equivale, nesse estudo, a dizer que sempre se contrata sob condições de incerteza.A face arriscada e perigosa do contrato mira o incerto futuro, e o risco é um aspecto que se sobressai quando se observam as decisões.O que faz do contrato um processo de produção do futuro que possui seu próprio tempo e que produz uma (algumas) diferença(s).

Assim, acreditamos que a calculabilidade seja de fato mais um mito moderno (REDDY, 1996). Como inexiste ponto privilegiado de observação do qual se possa chegar a predições ou conclusões inequívocas (MOELLER, p. 249), o futuro resta sempre ignoto. Remanescempontos cegos ao observador como condição de possibilidade de toda observação e isso impede a eliminação daquilo que é arriscado ou perigoso através de cálculo.

Vimos que se ao risco se opõe, como alternativa, a segurança ele exibe um caráter negativo, ao passo que se inexiste opção segura, e a alternativa for o perigo, ele exibe um caráter positivo. A incerteza com relação ao futuro passa, então, a ser um recurso, que pode ser aproveitado através da contratação.

As observações feitas nessa pesquisa demonstram que a função do direito penetra em seus institutos. Isso permitiu dizer que o contrato é um instrumento de estabilização de expectativas normativas. Dessa forma fica afastado do contrato qualquer caráter necessário de cumprir a tarefa impossível de dar segurança bem como a tarefa, repetidamente frustrada, de promover o valor 
igualdade.Valores tradicionalmente percebidos como funções ou objetivos do direito pela doutrina tradicional mas que na teoria dos sistemas são alocados sob a rubrica "autodescrições do sistema jurídico".

Assim é que, ao nos depararmos na doutrina dos contratos com a questão da igualdade dos contratantes e a da suposta vocação dos contratos para realizar o princípio da igualdade, tivemos que reconhecer a fragilidade desse entendimento. Não que o contrato deva ficar alheioà igualdade (formal, material etc.). Mas a eliminação da desigualdade é uma tarefa inatingível seja pelo contrato seja por outros meios. E assim é que desde o início de sua formulação moderna o contrato não tem podido seguir essa vocação que lhe supõem.

A decisão contratual produz diferenças: exclusão e inclusão, risco e perigo, passado e futuro. De princípio se percebe que ela, ao incluir os pactuantes em uma relação jurídica, exclui todos os demais.Projeta um futuro, reduzindo o escopo de arbitrário que há no povir, pense-se em uma matrícula em uma faculdade, em um plano de saúde, na compra de um imóvel, nas várias modalidades de seguro, todas essas operações que transformam a vida dos indivíduos, e que são pactuadas junto às organizações, tendo em vista um projeto de vida. Mas o contrato está sujeito a seus próprios riscos além de estar sujeito aos perigos do ambiente e de ser ele próprio um fator de perigo para os terceiros.

Ficou o registro também de que vivemos dentro de organizações a maior parte de nossas vidas, elas são parte significativa de nosso ambiente. E boa parte dos contratos são entabulados com as organizações, nas quais eles integram, por serem decisões, a sua própria autopoiese. Dessa forma é que nossa pesquisa do risco nos contratosfoi encontrando um caminho. Primeiro a ideia do risco fez perceber o contrato como decisão. Em seguida a questão da decisão levou a inquirir sobre as organizações. Um ponto que merece, futuramente, mais atenção: não existem organizações sem suas operações autopoiéticas, as decisões, portanto tampouco elas existem sem contratos.

Revelou-se ainda nesse trabalho que certos valores como segurança e até mesmo a igualdade devem ser alocados à conta de mitologias modernas, fruto de dois séculos de uma propaganda vitoriosa (GROSSI, 2004), o que deve ser decepcionante para quem se acostumou, como o direito e as organizações, a ver o seu próprio sentido na segurança, que não passa de ilusão.

\section{REFERÊNCIAS BIBLIOGRÁFICAS}

ANDERSEN. Niels Åkerstrøm. Understanding Foucault, Koselleck, Laclau, Luhmann. Bristol: The Policy Press, 2003. 
BANDEIRA DE MELLO, Celso Antônio. Grandes temas de direito administrativo. 2. Tiragem. São Paulo: Malheiros, 2010.

BARALDI, Claudio. CORSI, Giancarlo. ESPOSITO. Elena. Luhmann in Glossario: I concettifondamentalidella teoria dei sistemi social. Milano: FrancoAngeli, 1996. p. 31-33

BECK, Ulrich. Sociedade de risco: Rumo a uma outra modernidade. Tradução de Sebastião Nascimento. 2. ed. São Paulo: Editora 34, 2011.

BECK, Ulrich. Sociedade de Risco Mundial: Em busca da segurança perdida. Lisboa: Editora 70,2016

CLAM, Jean. Questões fundamentais de uma teoria da sociedade: Contingência, paradoxo, sóefetuação. Tradutor: Nélio Schneider. São Leopoldo: Editora Unisinos, 2006

COELHO, Fábio Ulhoa. O empresário e os direitos do consumidor. $O$ cálculo empresarial na interpretação do Código de Defesa do Consumidor. São Paulo: Saraiva, 1994.

DANTAS, F.C. de San Tiago. Problemas de Direito Positivo. Rio de Janeiro: Forense, 1953.

DE GIORGI. Raffaele. O risco na sociedade contemporânea. Revista de Direito Sanitário. São Paulo. V.9, n.1 p. 37-49, Mar./Jun.2008

DENNEY, David. Risk and Society.London, Thousand Oaks, New Delhi: SAGE Publications, 2005.

ESPOSITO, Elena. The future of futures: the time of Money in financing and society. Tradução de Elena Esposito com auxílio de Andrew K. Whitehead. Cheltenham: Edward Elgar, 2011.

FERRAZ JR. Tercio Sampaio. Função Social da Dogmática Jurídica. 2. ed.São Paulo: Editora Atlas, 2015.

FERREIRA, Fernanda Busanello. O risco nas teorias sociológicas contemporâneas: Beck, Giddens e Luhmann. Raízes Jurídicas. Curitiba. V. 7. N. 2. Jul./dez. 2011.

GROSSI, Paolo. Mitologias jurídicas da modernidade. Tradução de Arno Dal Ri Júnior. Florianópolis: Fundação Boiteux, 2004.

KERMISCH, Céline. Vers une définition multidimensionnelle du risque. VertigO - la revue électronique en sciences de l'environnement. V.12. n. 2. Sept. 2012.

KNIGHT, Frank H. Risk, Uncertainty and Profit. New York: Cosimo Classics, 2005. Kindle edition.

LASH. Scott.Individualization in a non linear mode.in BECK, Ulrich. BECK-GERNSHEIN, Elisabeth. Individualization: Institutionalized individualismo and its social and political consequences. London, Thousand Oaks, New Delhi: SAGE Publications, 2002

LUHMANN, Niklas. Sociologia do direito II. Rio de Janeiro: Tempo Brasileiro, 1983

LUHMANN, Niklas. The paradoxof form. In: BAECKER, Dirk. Problems of form. Translated by Michael Irmscher, with Leah Edwards. Stanford: Stanford University Press, 1999. p. 15-26. 
LUHMANN, Niklas. Inclusão e exclusão. In: DUTRA, Roberto. BACHUR, João Paulo. Dossiê NiklasLuhmann. Belo Horizonte: Editora UFMG, 2013.

LUHMANN, Niklas. La sociedad de la sociedad. Traducción de Javier Torres Nafarrate. Ciudad de México: Herder, 2006.

LUHMANN, Niklas. Identity: What or how? inTheories of distinction: redescribing the descriptions of modernity. Edited, with an Introduction, by William Rasch. Stanford, California: Stanford University Press, 2002.

LUHMANN, Niklas. El derecho de lasociedad. 2.ed. Tradução de Javier Torres Nafarrate, BrunhildeErker, Silvia Pappe e LuisFlipe Segura. Mexico: Herder; UniversidadIberoamericana, 2005.

LUHMANN, Niklas. Sistemas sociais: esboço de uma teoria geral. Petrópolis: Vozes, 2016a.

LUHMANN, Niklas. Risk: A sociological theory. Translated by Barrell Rhodes.London and New York: Routledge, 2017.

LUPTON, Deborah. Risk. New York and London: Routlegde, 2005.

LUZ, Cícero Krupp da. SIMIONI, Rafael Lazzarotto. Decisão, organização e risco: a positividade do direito na formação da decisão jurídica. Conpedi Law Review. Uruguai. V.2. n. 4. p. 318-334. Jul/Dez.2016.

MARCH, James. SIMON, Herbert. Organizations.2nd. ed. Oxford: Blackwell Business, 1993.

MENDES, José Manuel. Sociologia do risco: uma breve introdução e algumas lições. Coimbra: Imprensa da Universidade de Coimbra, 2015.

MOELLER, Hans-Georg.The radical Luhmann.N.Y. Columbia University Press, 2012.

MYTHEN, Gabe. Ulrich Beck: a critical introduction to the risk society. London: Pluto Press, 2004.

MYTHEN, Gabe..Beyond the risk society: critical reflexions on risk and human security. London: Open University Press, 2006. 254 p.

NALIN, Paulo. Do contrato: conceito pós-moderno. 5. tir. Curitiba: Juruá, 2005.

NUNES, António José Avelãs. A revolução francesa: as origens do capitalismo a nova ordem jurídica burguesa. Belo Horizonte: Fórum Conhecimento Jurídico, 2017.

ROCHA. L.S, AVEZEDO, G. Notas para uma teoria da organização da decisão jurídica autopoiética. Rechts. São Leopoldo. V. jul. dez. 2012.

ROPPO, Enzo. O contrato. Tradução de Ana Coimbra e M. Januário C. Gomes. Coimbra: Almedina, 2009.

OST, François. Le Temps du Droit. Paris: Odile Jacob, 1999.

PERLINGIERI, Pietro. Perfis do direito civil. Introdução ao direito civil constitucional. 3. ed. Rio de Janeiro, São Paulo, Recife: Renovar, 2007.

PRADIER, Pierre-Charles, SERRANO, David Teira. Frank H. Knight, Le risque come critique de 1'économie politique. Revue de Synthèse. 4'. n. 1-2, janv. -juin. 2000. p. 79-116. 
REDDY, S. (1996) Claims to expert knowledge and the subversion of democracy: the triumph of risk over uncertainty. Economy and Society, 25(2), 222-54.

RESCHER, Nicholas. Risk: a philosophical introduction to the theory of risk evaluation and management. Washington: University Press ofAmerica, 1983.

SPENCER-BROWN, George. Laws of form.New York: Dutton, 1979.

SCHREIBER, Anderson. Equilíbrio contratual e dever de renegociar. São Paulo: Saraiva Educação, 2018. Edição Kindle.

SIMIONI, Rafael Lazzarotto. Curso de Hermenêutica Jurídica Contemporânea: do positivismo clássico ao pós-positivismo jurídico. Curitiba: Juruá, 2014.

SIMIONI, Rafael Lazzarotto. Decisão, organização e risco: a forma da decisão jurídica para além da segurança e da legitimidade. Revista do programa de Pós-Graduação em Direito da UFC. v.37.1. jan./jun. 2017, p. 259-279

SMITHSON, MICHAEL. Ignorance and Uncertainty.Emerging Paradigms.New York: Springer-Verlag, 1989.

TEUBNER, Günther. Direito, sistema e policontexturalidade. Tradução de Brunela Vieira de Vicenziet al. Piracicaba: Editora Unimep, 2005. 300, p. 